\title{
Ultrafine-Grained Al-Mg-Sc Alloy via Friction-Stir Processing
}

\begin{abstract}
NILESH KUMAR and RAJIV S. MISHRA
Friction-stir processing (FSP) of twin-roll cast (TRC) Al-Mg-Sc alloy resulted into ultrafinegrained microstructure. The alloy was processed in as-received and aged $\left(563 \mathrm{~K}\left[290{ }^{\circ} \mathrm{C}\right]\right.$, 22 hours) conditions and at three different tool rotation rates: 800, 400, and $325 \mathrm{rpm}$. The microstructural features were characterized using electron backscattered diffraction (EBSD), scanning electron microscopy (SEM), and transmission electron microscopy (TEM). The grain size varied from $0.89 \mu \mathrm{m}$ to $0.39 \mu \mathrm{m}$ depending on the processing and initial thermo-mechanical conditions of the alloy. The TRC alloy processed at $325 \mathrm{rpm}$ in aged condition had all the grains less than $1 \mu \mathrm{m}$, and 95 pct of grains had high-angle grain boundaries (HAGBs). In all the cases, the fraction of HAGBs were more than 80 pct. The variation of misorientation angle distribution was similar to the theoretical MacKenzie distribution for cubic crystal materials. Grain size analysis at different sections and locations on the transverse section of the dynamically recrystallized zone showed a homogeneous and equiaxed microstructure. The average dispersoid $\left(\mathrm{Al}_{3}(\mathrm{Sc}, \mathrm{Zr})\right)$ size was $\sim 8.0 \mathrm{~nm}$ in diameter obtained using high-resolution TEM. Grain size reduction was observed with increase in Zener-Hollomon parameter. It was shown that under the current microstructural and deformation conditions, dynamic recrystallization via particlestimulated nucleation might not be possible during FSP.
\end{abstract}

DOI: $10.1007 / \mathrm{s} 11661-012-1461-5$

(C) The Minerals, Metals \& Materials Society and ASM International 2012

\section{INTRODUCTION}

EASY accessibility of an ultrafine-grained (UFG) regime by the current processing techniques have spurred research and development activities to better understand the physical, chemical, and mechanical properties of UFG materials. ${ }^{[1-5]}$ Researchers all across the world are actively pursuing the research to understand the entire spectrum of properties of UFG materials. Among others, mechanical behavior is of paramount importance for structural application. The microstructure and mechanical properties are intertwined. Hence, equal efforts are being made to develop microstructures in a controlled way to meet a desired level of mechanical property requirements.

The techniques to obtain UFG materials are classified in two basic categories: the bottom-up approach and the top-down approach. The details of these can be found elsewhere. ${ }^{[6,7]}$ Severe plastic deformation (SPD) is a topdown approach and has been widely explored as a means to develop bulk ultrafine-grained materials. ${ }^{[6,8-14]}$ Equalchannel angular pressing (ECAP) ${ }^{[6,8]}$ high-pressure torsion (HPT) ${ }^{[9]}$ accumulative roll bonding (ARB) ${ }^{[10,11]}$ friction-stir processing (FSP) ${ }^{[12-14]}$ etc., are some prime examples of SPD techniques. Among these, FSP is relatively new and slightly different from other SPD techniques. Unlike others, it can be considered as a hightemperature SPD technique due to the high temperature

NILESH KUMAR, Postdoctoral Research Associate, and RAJIV S. MISHRA, Professor, are with the Department of Materials Science and Engineering, Center for Friction Stir Processing, University of North Texas, Denton, TX 76203. Contact e-mail: Rajiv.Mishra@ unt.edu

Manuscript submitted May 23, 2012.

Article published online October 17, 2012 involved because of frictional and adiabatic heating during processing of a material. Also, in comparison to other techniques, this is a relatively less explored technique, and efforts are being made to process UFG materials using FSP and understand their mechanical properties.

FSP has emerged as a generic microstructure modification tool in the last decade. All the initial attempts to refine grain size by FSP were limited to fine-grained microstructure (1 to $10 \mu \mathrm{m}) .^{[15]}$ Mishra and $\mathrm{Ma}^{[15]}$ have tabulated the grain sizes obtained by FSP or friction-stir welding (FSW) under various processing conditions. It is clear from the experimental conditions and resulting grain size that an external cooling medium or a special design of tool was required to obtain UFG microstructure. Of late, there have been some efforts to obtain UFG microstructure by changing the processing parameters such as tool rotational rate $(\omega)$ at constant tool traverse velocity $(v)$ or the ratio $\omega / v^{[12,16,17]}$

Su et $a l^{[18]}$ and Rhodes et al. ${ }^{[19]}$ demonstrated the possibility of achieving grains as small as 25 to $100 \mathrm{~nm}$ by employing special cooling arrangement during FSP. But as mentioned earlier, most of the mean grain sizes tabulated by Mishra and Ma were larger than $1 \mu \mathrm{m}$ under ordinary processing conditions. ${ }^{[15]}$ Hence, these observations are indicative of coarsening of grains during FSP/FSW. In fact, Rhodes et al. ${ }^{[19]}$ obtained 2 to $5 \mu \mathrm{m}$ grain size after heating the samples having initial grain sizes in the range 25 to $100 \mathrm{~nm}$ at $523 \mathrm{~K}$ to $623 \mathrm{~K}\left(250{ }^{\circ} \mathrm{C}\right.$ to $\left.350{ }^{\circ} \mathrm{C}\right)$ for 1 to 4 minutes. Being a high-temperature process, nanosized grains formed during FSP grow very rapidly under the influence of thermal cycle when no forced cooling is imposed. Due to this, the real potential of FSP for microstructural refinement cannot be tapped. Use of external cooling 
media necessitates extra fixtures during processing, and their use may not be feasible in every condition.

The presence of precipitates or dispersoids is known to inhibit the grain growth via Zener pinning. Hence, the untapped potential of FSP can be exploited not only by controlling the processing parameters but also by using a material that either contains thermally stable precipitates or dispersoids, or can precipitate out such particles during processing thereby retarding the uncontrolled grain growth during processing. Hence, UFG microstructure may be obtained by controlling the grain growth by the use of precipitates or dispersoids during FSP. The current research deals with this. A newly developed Al-Mg-Sc alloy was processed using FSP to obtain UFG microstructure. The characteristics of UFG microstructure obtained via FSP are entirely different from those obtained by conventional SPD techniques. A microstructure with equiaxed, homogeneous, and a completely random distribution of grains was obtained.

\section{EXPERIMENTAL}

A twin-roll cast (TRC) Al-Mg-Sc alloy sheet ( $\sim 3.75 \mathrm{~mm}$ thickness) was processed using FSP. The nominal composition of the alloy was Al- $4 \mathrm{Mg}-0.8 \mathrm{Sc}-$ $0.08 \mathrm{Zr}$, wt pct. The alloy was processed in two different thermomechanical conditions - as-received (AR) and $\mathrm{AR}+$ aged. The aging was carried out at $563 \mathrm{~K}$ $\left(290{ }^{\circ} \mathrm{C}\right)$ for 22 hours. The material processed in the AR condition will be referred to as AR + FSP $(\omega)$ and the one in aged condition as aged + FSP $(\omega)$. Here, $\omega$ stands for tool rotation rate (revolution per minute, rpm). $\omega$ will be replaced with appropriate value while making reference to a particular tool rotation rate. A tool steel tool was used to process the material. The geometrical details of the tool are provided in Table I. Three different tool rotational rates were used- $800 \mathrm{rpm}, 400 \mathrm{rpm}$, and $325 \mathrm{rpm}$ - to process the material. In each case, other processing parameters such as tool traverse speed, tool tilt angle, and plunge depth were kept constant. The tool traverse speed, tool tilt angle, and plunge depth were $3.4 \mathrm{~mm} / \mathrm{s}$ (8 ipm), $2.5 \mathrm{deg}$, and $2.5 \mathrm{~mm}(0.097$ "), respectively.

FSP resulted in the grain refinement. The microstructural information such as grain size, its distribution, misorientation angle distribution, etc. were obtained using electron backscatter diffraction (EBSD) using an HKL EBSD system fitted on FEI Helios NanoLab 600 FIB/FESEM (FEI Company, Hillsboro, OR). Each sample was mechanically polished using water-based diamond suspension up to $1 \mu \mathrm{m}$ grit size and final polishing on $0.02 \mu \mathrm{m}$ using colloidal silica suspension.
EBSD was carried out in as-polished condition. In AR and FSP conditions, a step-size of $1 \mu \mathrm{m}$ and $0.1 \mu \mathrm{m}$, respectively, were chosen.

The primary $\mathrm{Al}_{3}(\mathrm{Sc}, \mathrm{Zr})$ dispersoids in as-received condition and after FSP were characterized using a scanning electron microscope (SEM). Transmission electron microscope (TEM) was used to characterize secondary nanosized $\mathrm{Al}_{3}(\mathrm{Sc}, \mathrm{Zr})$ dispersoids. A $2-\mathrm{mm}$ disk was thinned down to $80 \mu \mathrm{m}$ followed by electropolishing in a twin-jet polisher. Electropolishing was carried out at $30 \mathrm{~V}$ and $243 \mathrm{~K}\left(-30^{\circ} \mathrm{C}\right)$. A mixture of $\mathrm{CH}_{3} \mathrm{OH}$ and 20 pet $\mathrm{HNO}_{3}$ was used as an electrolyte.

\section{RESULTS}

\section{A. Grain Refinement}

The EBSD micrograph for AR and grain size distribution (GSD) histogram and cumulative GSD curve for AR and AR + FSP (325 rpm) TRC alloy are shown in Figure 1. The thick dark lines in the micrograph (Figure 1(a)) represent high-angle grain boundaries (HAGBs) and thin black lines low-angle grain boundaries (LAGBs). ${ }^{[20]}$ The average grain size in AR condition was $19 \mu \mathrm{m}$. The maximum grain size observed in this condition was $122 \mu \mathrm{m}$. Due to the large variability in grain size, the standard deviation was found to be $27 \mu \mathrm{m}$. The standard deviation larger than the average grain size is indicative of the presence of very large grains in the alloy microstructure. The GSD histogram and cumulative GSD curve for this condition can be seen in Figure 1(c). The GSD histogram and cumulative GSD curve for AR + FSP (325) are shown in Figure 1(d). It should be noted in this figure that all the grains were smaller than $1.6 \mu \mathrm{m}$. The fraction of grains below $1 \mu \mathrm{m}$ was 99 pct. The average grain size in this condition was $0.49 \mu \mathrm{m}$ and the standard deviation was found to be $0.23 \mu \mathrm{m}$. Evidently, FSP of this alloy resulted into not only a substantial refinement in grain size but also a considerable reduction in standard deviation.

The misorientation-angle distribution (MAD) curves for these conditions are shown in Figure 2. All the boundaries having misorientation above 2 deg have been included in the current analysis. Two different types of MAD curves have been included into the analysis: correlated and uncorrelated. ${ }^{[21]}$ For the purpose of performing a comparison, MacKenzie distribution curve ${ }^{[22]}$ (for a cubic, randomly oriented polycrystalline material) is overlaid in Figure 2. In the AR condition, the fraction of grains having HAGB (misorientation angle $>15 \mathrm{deg}$ ) obtained by correlated

Table I. Details of the Tool Material and its Geometry

\begin{tabular}{|c|c|c|c|c|c|c|c|}
\hline \multirow[b]{2}{*}{$\begin{array}{l}\text { Tool } \\
\text { Material }\end{array}$} & \multirow[b]{2}{*}{$\begin{array}{l}\text { Pin Height } \\
(\mathrm{mm})\end{array}$} & \multicolumn{2}{|c|}{ Pin Diameter, $D_{\text {pin }}(\mathrm{mm})$} & \multirow[b]{2}{*}{$\begin{array}{c}\text { Shoulder Diameter, } \\
D_{\text {shoulder }}(\mathrm{mm})\end{array}$} & \multirow[b]{2}{*}{ Pin Profile } & \multirow[b]{2}{*}{$\begin{array}{l}\text { Shoulder } \\
\text { Profile }\end{array}$} & \multirow[b]{2}{*}{$\tan (\alpha)$} \\
\hline & & $\begin{array}{l}\text { Near the tip } \\
\text { of the tool }\end{array}$ & $\begin{array}{l}\text { Near the root } \\
\text { of the pin }\end{array}$ & & & & \\
\hline Tool steel & 2.20 & 3.75 & 6.00 & 12.0 & step spiral & concave & 0.067 \\
\hline
\end{tabular}




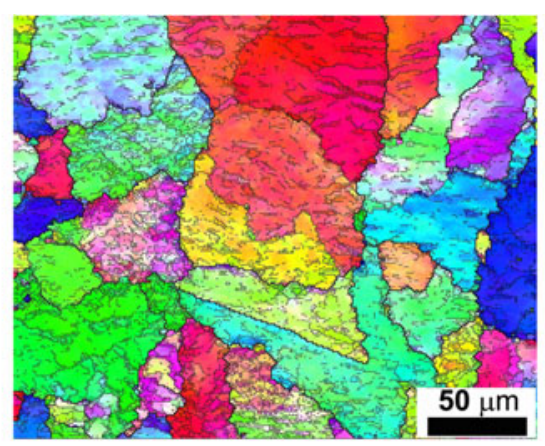

(a)

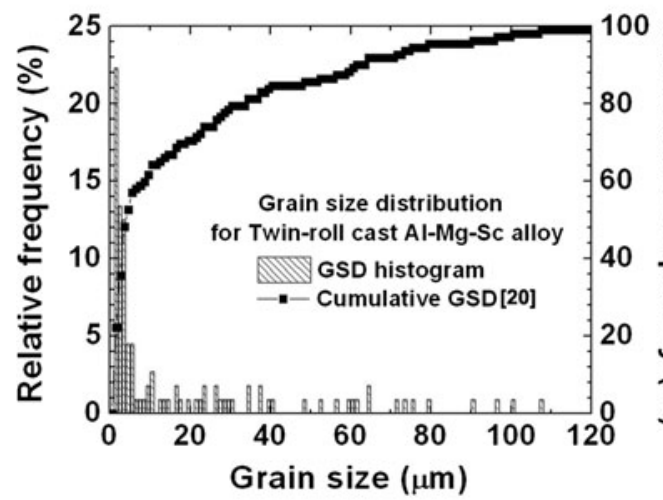

(c)

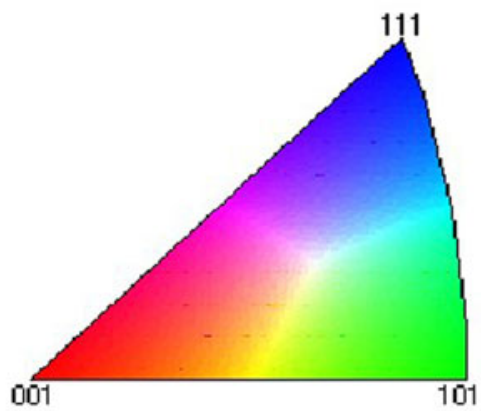

(b)

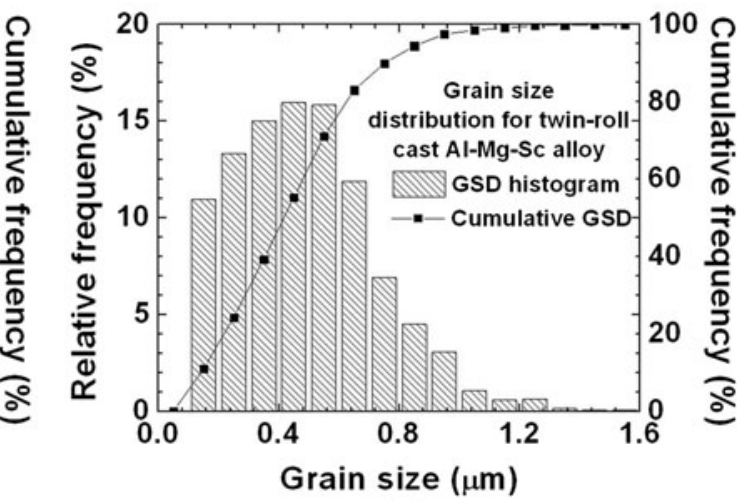

(d)

Fig. 1-(a) EBSD micrograph of TRC Al-Mg-Sc in the AR condition ${ }^{[20]}$ and $(b)$ inverse pole figure for correlating crystallographic axes associated with each color with TRC direction; GSD histograms and cumulative GSD curves for TRC alloy in $(c)$ AR and (d) AR + FSP (325 rpm) conditions.

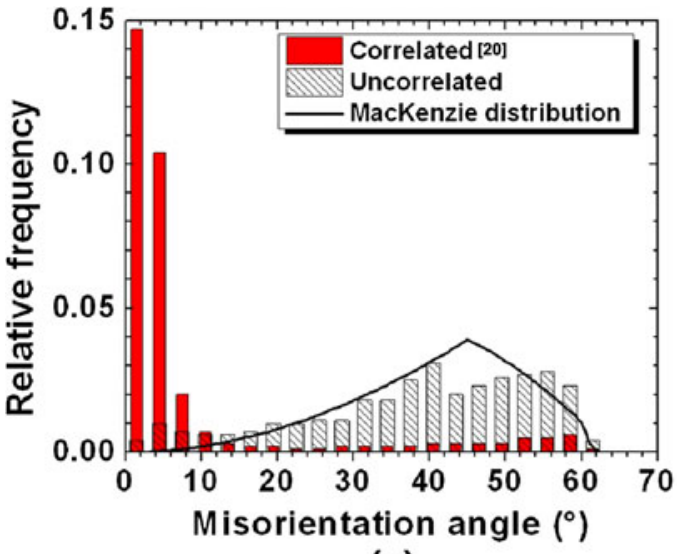

(a)



(b)

Fig. 2-Misorientation-angle distribution (MAD) of TRC Al-Mg-Sc alloy in (a) AR and (b) AR + FSP (325 rpm) conditions.

MAD analysis was 13 pct, whereas it was $\sim 90$ pct obtained by uncorrelated MAD analysis. Such a large difference in the fraction of HAGB obtained by these two methods indicates that AR TRC alloys contain a high fraction of substructure (subgrains, dislocation cells, etc.) within the grains having HAGB. This analysis was carried out for FSP sample also. The fraction of HAGB obtained by correlated and uncorrelated MAD analysis was $\sim 90$ pct and $\sim 96$ pct, respectively. Such a small difference in fraction of HAGB obtained by these two methods and such a high fraction of HAGB is indicative of substructure free grain interiors. TEM studies have shown a low dislocation density in the dynamically recrystallized region of processed materials. ${ }^{[18,23,24]}$ The average grain misorientation angles estimated by correlated and uncorrelated methods were $8.7 \mathrm{deg}$ and $38.6 \mathrm{deg}$, respectively, in the AR condition. In FSP condition, it was $37.1 \mathrm{deg}$ and $40.1 \mathrm{deg}$ 


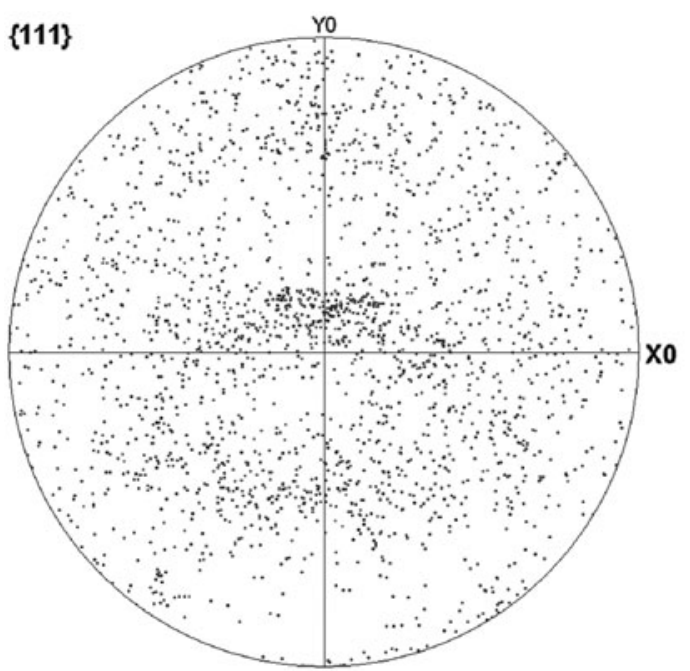

(a) As-received

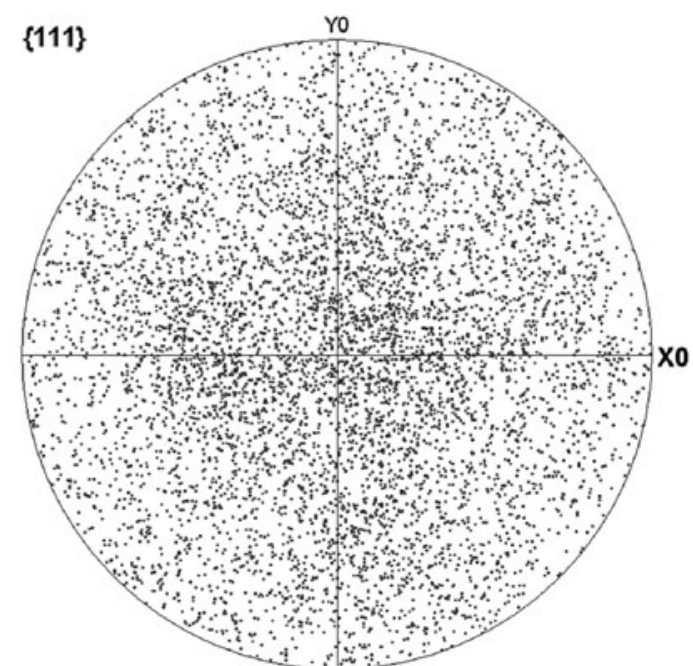

(b) FSP

Fig. 3-(111) pole figure for (a) AR and (b) AR + FSP (325) TRC Al-Mg-Sc alloy.

estimated by correlated and uncorrelated methods, respectively. The average grain misorientation angle for MacKenzie distribution is $42.3 \mathrm{deg}$. The MacKenzie distribution represents a complete random distribution of grains belonging to cubic crystal system. ${ }^{[22]}$ A close proximity of uncorrelated average misorientation angles of AR and AR + FSP (325) to the average misorientation angle for MacKenzie distribution is suggestive of the presence of a random microstructure in both the conditions.

The presence of a completely random microstructure was confirmed by plotting (111) pole figures for AR and FSP alloy (Figure 3). (111) poles in both the cases appear randomly distributed. If any of these were textured, then (111) poles would have appeared in pockets or clusters on the pole figure.

\section{B. Effect of Processing Parameters on Grain Size Evolution}

As previously mentioned, three different tool rotation rates - 800, 400, and $325 \mathrm{rpm}$ - were used to study the effect of processing parameters on the grain size evolution. The tool rotation rate has major influence on heat input during processing of the material. It, in turn, determines the peak temperature that can be reached during processing. Peak temperature ultimately determines the mean grain size obtained and distribution of grains. The results from this study are shown in Figure 4. It should be noted here that all the orientation imaging micrographs (OIMs) shown here were taken on the transverse section of the FSP nugget. The color associated with each grain represents a specific crystallographic direction that can be inferred from the accompanying inverse pole figure (IPF). All the crystallographic axes are parallel to FSP direction (Y0), which is here perpendicular to the plane of the paper. The visual comparison of OIMs indicates that the grain size became finer and finer as the tool rotation rate decreased. At $800 \mathrm{rpm}$, the mean grain size was $0.89 \pm 0.62 \mu \mathrm{m}$. It reduced to $0.73 \pm 0.44 \mu \mathrm{m}$ and $0.49 \pm 0.23 \mu \mathrm{m}$ when processed at $400 \mathrm{rpm}$ and $325 \mathrm{rpm}$, respectively. From the standard deviation values, it is clear that a decrease in tool rotation rate caused a reduction of grain size scatter also.

The cumulative grain size distribution curves related to these three processing parameters are documented in Figure 5(a). It shows that almost all the grains were below $1 \mu \mathrm{m}$ at $325 \mathrm{rpm}$. However, the fraction of grains below $1 \mu \mathrm{m}$ was 81 pct and 71 pet for materials processed at 400 and $800 \mathrm{rpm}$, respectively. Clearly, the effect of tool rotation rate can be seen on the grain size distribution too. Generally, UFG material is defined as mean grain size less than $1 \mu \mathrm{m} .{ }^{[6]}$ Hence, on the basis of mean grain size, it can be stated that each tool rotation rate resulted in formation of UFG microstructure. However, for the material processed at $325 \mathrm{rpm}$, almost all the grains were less than $1 \mu \mathrm{m}$. Hence, this processing parameter resulted in a truly UFG microstructure. All the above observations have been summarized in pictorial format in Figure 5(b). It shows the variation of mean grain size $\left(d_{\mathrm{av}}\right)$, standard deviation $(\sigma)$, and fraction of grains less than $1 \mu \mathrm{m}$ as a function of tool rotation rate $(\omega)$.

\section{Effect of Initial Microstructure on Grain Size Evolution}

The effect of initial microstructure on grain size evolution was studied by aging the TRC alloy at $563 \mathrm{~K}\left(290{ }^{\circ} \mathrm{C}\right)$ for 22 hours. Aging heat treatment resulted into precipitation of $\mathrm{Al}_{3}(\mathrm{Sc}, \mathrm{Zr})$ dispersoids. This study was carried out at all three tool rotation rates mentioned in the previous section. The result from this study has been shown in Figure 6 in the form of cumulative grain size distribution. For the purpose of performing a comparison, the result from the Section III-B has also been superimposed. The mean grain sizes were $0.79 \pm 0.50 \mu \mathrm{m}, 0.63 \pm 0.33 \mu \mathrm{m}$, 


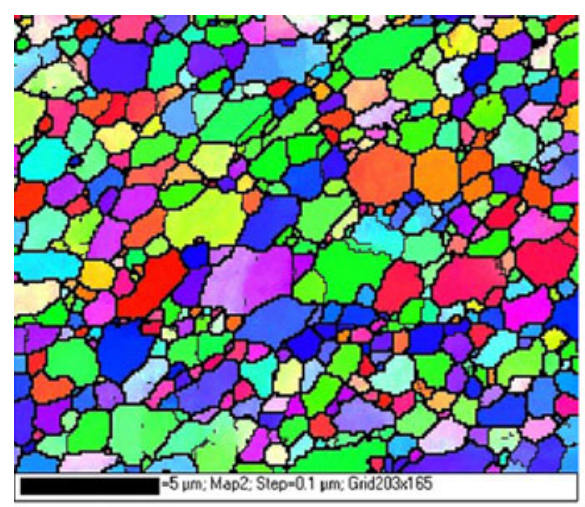

(a)

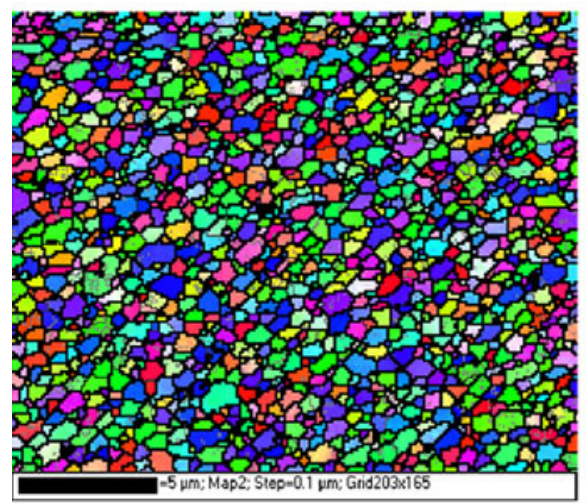

\section{(c)}

Fig. 4 -EBSD micrographs of TRC Al-Mg-Sc alloy processed in AR condition at (a) $800 \mathrm{rpm},(b) 400 \mathrm{rpm}$, ${ }^{[20]}$ and $(c) 325 \mathrm{rpm} . \mathrm{Y} 0 \mathrm{represents}$ the FSP direction that is here perpendicular to the plane of the paper.

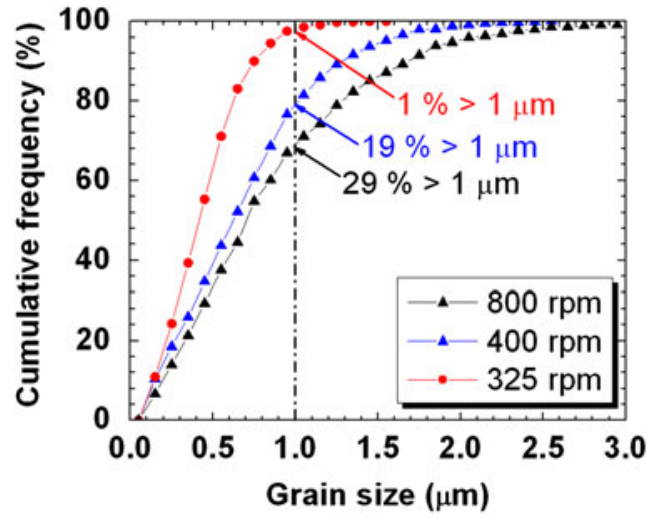

(a)

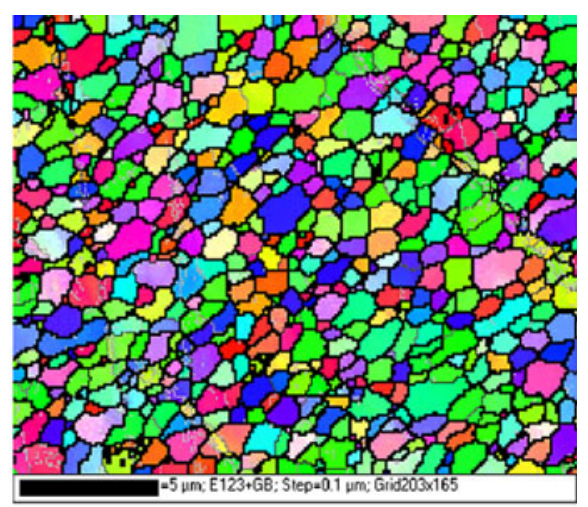

(b)

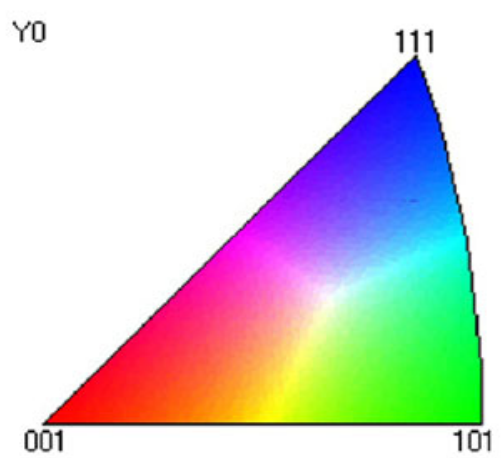




\section{Microstructural Homogeneity}

Microstructural homogeneity of the FSP region was studied at different cross sections (longitudinal- $X Z$ plane, transverse- $Y Z$ plane, and top- $X Y$ plane) and on the transverse cross section at various locations within the dynamically recrystallized region. This study was carried out on a material processed in AR condition at $325 \mathrm{rpm}$. At longitudinal ( $X Z$ plane), transverse
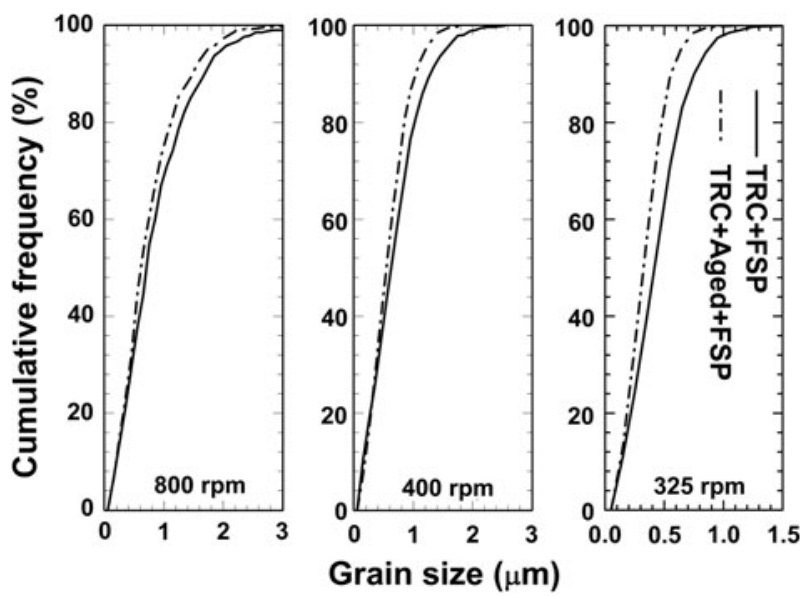

Fig. 6- Cumulative GSD curves of aged + FSP alloy processed at $800 \mathrm{rpm}, 400 \mathrm{rpm},{ }^{[25]}$ and $325 \mathrm{rpm} \cdot{ }^{[25]}$ Also shown are corresponding GSD curves of AR + FSP TRC Al-Mg-Sc alloy.

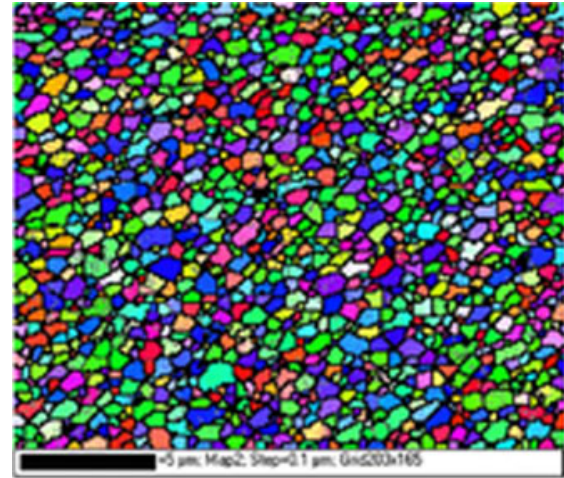

(a)

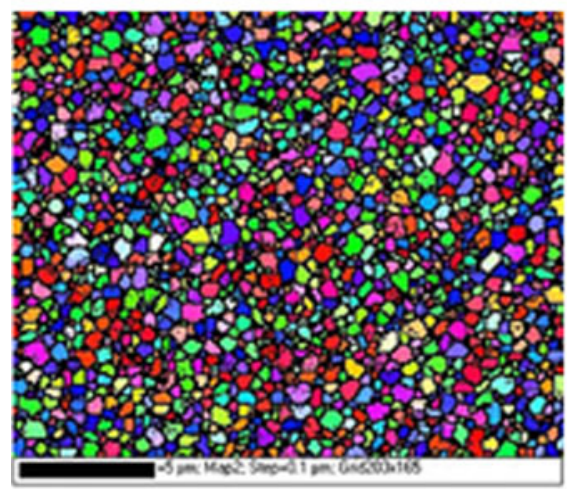

(c)
( $Y Z$ plane), and top ( $X Y$ plane) sections grain sizes were $0.44 \pm 0.20 \mu \mathrm{m}, 0.49 \pm 0.23 \mu \mathrm{m}$, and $0.46 \pm 0.25 \mu \mathrm{m}$, respectively. So, all three sections contained almost the same mean grain size. The OIM micrographs are shown in Figure 7. The location of the microscopy is shown in the accompanying schematic diagram.

The results of microstructural examination on the transverse section of the material processed at $325 \mathrm{rpm}$ in AR condition are shown in Figure 8. The accompanying schematic of transverse cross section relates each OIM to its location in the nugget. $\mathrm{X}$ represents the midpoint, which is $1.25 \mathrm{~mm}$ below the top surface of the nugget. Also shown in the same schematic diagram is the distance from the midpoint $\mathrm{X}$ of the center points of locations at which these OIMs were mapped. The corresponding OIM images are shown in the same figure. The average grain size at locations $1,2,3$, and 4 were $0.48 \pm 0.22 \mu \mathrm{m}, 0.48 \pm 0.24 \mu \mathrm{m}, 0.49 \pm 0.24 \mu \mathrm{m}$, and $0.42 \pm 0.20 \mu \mathrm{m}$, respectively. Clearly, FSP led to the development of very homogeneous microstructure within the dynamically recrystallized zone.

\section{E. Effect of FSP on $\mathrm{Al}_{3}(\mathrm{Sc}, \mathrm{Zr})$ Dispersoids}

The current Al-Mg-Sc alloy consists of 0.8 wt pet Sc due to which it is a hypereutectic alloy. ${ }^{[26]}$ Hence, during casting of this alloy, solidification of primary $\mathrm{Al}_{3}(\mathrm{Sc}, \mathrm{Zr})$ dispersoids should be expected. Primary $\mathrm{Al}_{3}(\mathrm{Sc}, \mathrm{Zr})$ dispersoids size distribution was carried out using SEM,

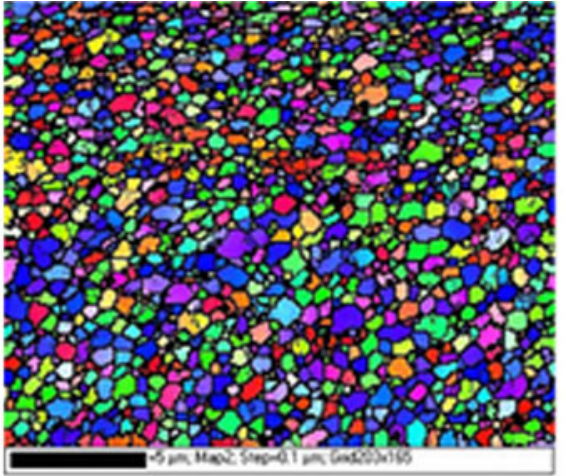

(b)

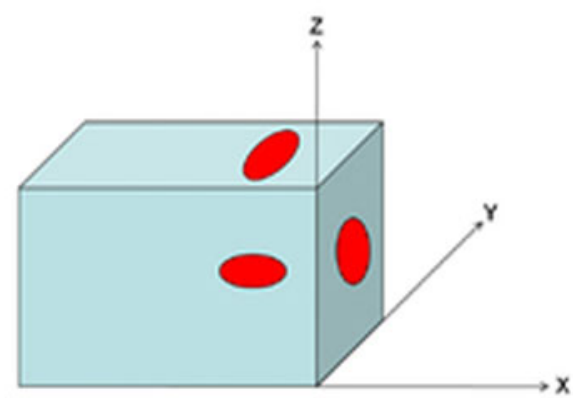

(d)

Fig. 7-EBSD images showing microstructure at different sections ( $X Z, Y Z$, and $X Y$ planes) for materials processed at 325 rpm in AR condition: $(a)$ transverse ( $Y Z$ plane), $(b)$ longitudinal ( $X Z$ plane), and $(c)$ top ( $X Y$ plane). The information embedded with different colors have the same meaning as for the OIMs shown in Fig. 4. 


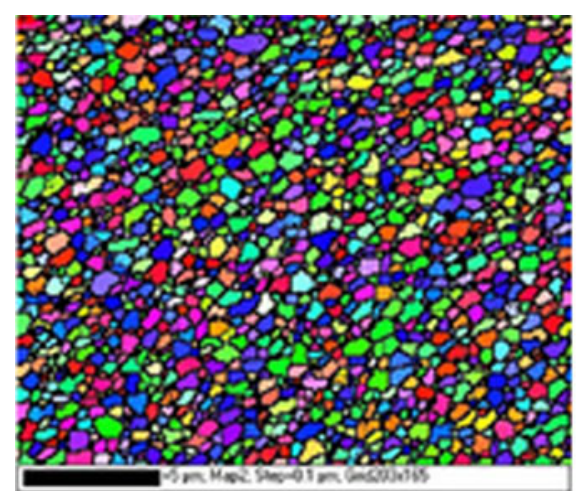

(a)

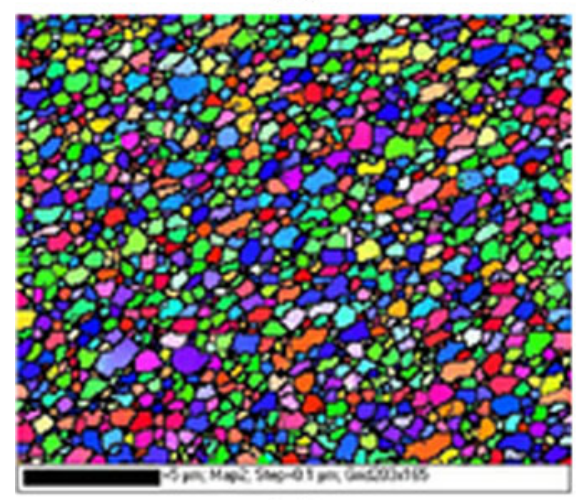

(c)

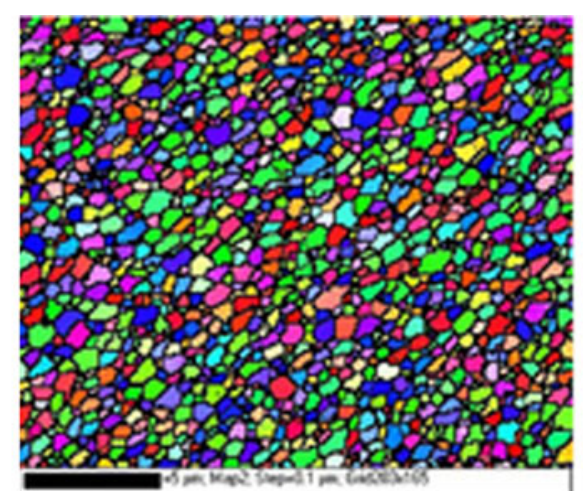

(b)

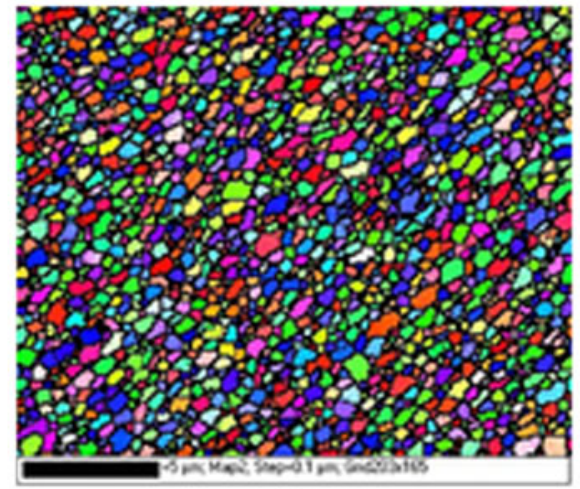

(d)

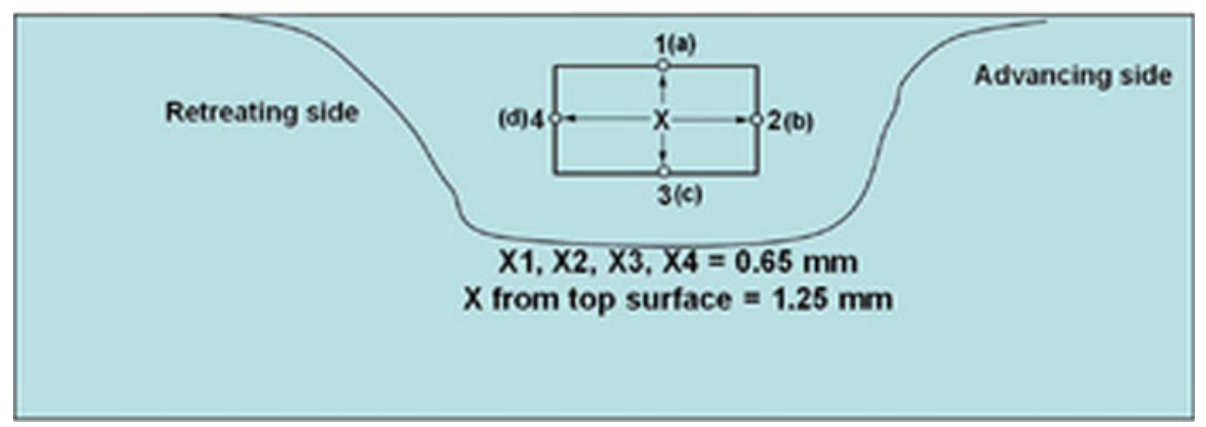

Fig. 8-The EBSD images taken at various locations in the nugget. The locations within the nugget are shown in the accompanying schematic transverse cross section of the processed volume.

and the results are summarized in Figure 9. The $\mathrm{Al}_{3}(\mathrm{Sc}, \mathrm{Zr})$ dispersoid size after FSP at $400 \mathrm{rpm}$ is also superimposed in Figure 9. It is evident that FSP resulted in the refinement of these dispersoids. In twin-roll casting, the cooling rate is generally very fast $(>100 \mathrm{~K} / \mathrm{s})$. This will cause retention of Sc in Al matrix as solid solution. ${ }^{[26]}$ Subsequent heat treatment may cause it to precipitate. Hence, during aging or FSP, secondary $\mathrm{Al}_{3}(\mathrm{Sc}, \mathrm{Zr})$ dispersoids will precipitate out. These are nanosized dispersoids. A dark-field TEM image and corresponding diffraction pattern is included in Figures 10(a) and (b). It is evident from Figure 10(a) that these secondary dispersoids are approximately 5 to $20 \mathrm{~nm}$ in size. A high-resolution TEM image showing 8.0- $\mathrm{nm}$ sized $\mathrm{Al}_{3}(\mathrm{Sc}, \mathrm{Zr})$ dispersoid is included in Figure 10(c).

\section{DISCUSSION}

A. Grain Refinement and the Role of $\mathrm{Al}_{3}(\mathrm{Sc}, \mathrm{Zr})$ Dispersoids

It is now understood, based on the work of various researchers, that refined grain size ${ }^{[18,19,27]}$ during FSP/ FSW and observed grain sizes ${ }^{[15]}$ are distinctly different. The heating experiment of Rhodes et al. ${ }^{[19]}$ following FSP and the use of static grain growth model to estimate the grain size observed after FSP by Sato et al., ${ }^{[16]}$ Robson and Campbell, ${ }^{[28]}$ and Kumar et al. ${ }^{[29]}$ supports the above idea. There are primarily three ways by which grain size development during FSP has been controlled: (1) cooling rate control, (2) peak temperature control, and (3) use of thermally resistant precipitates/dispersoids. In reference to route (1), the works of Rhodes 
et al. ${ }^{[19]} \mathrm{Su}$ et al. ${ }^{[18,27]}$ Hofmann and Vecchio, ${ }^{[30]}$ and Mehranfar and Dehghani ${ }^{[31]}$ are worth noting. These researchers employed external cooling media to increase the rate of cooling during FSP which retarded grain growth kinetics in the wake of thermal heat. Application of external cooling medium has bearing only on cooling rate. It does not change the peak temperature. Hofmann

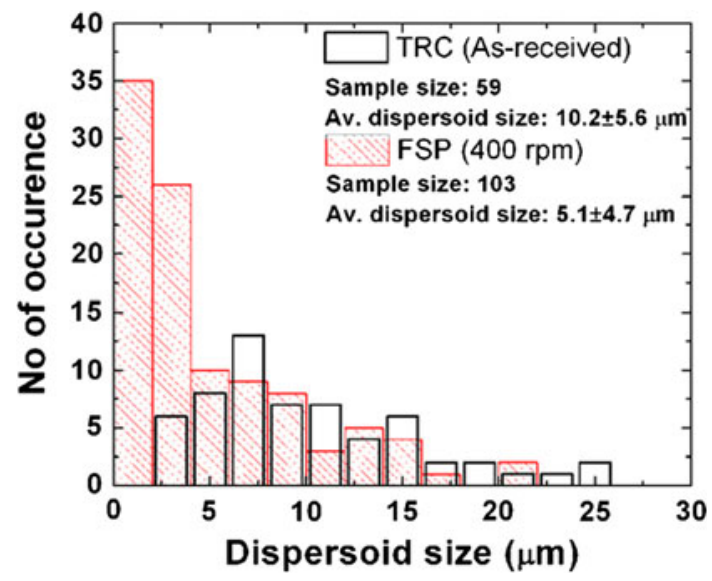

Fig. 9-Primary $\mathrm{Al}_{3}(\mathrm{Sc}, \mathrm{Zr})$ dispersoids size distribution histogram in as-cast and FSP conditions. and Vecchio ${ }^{[30]}$ processed $6061 \mathrm{Al}$ plate in air and water (submerged FSP - SFSP) and obtained a comparable peak temperature. The control of grain size by manipulating the peak temperature reached during FSP — mentioned as route (2) - has been tried by many researchers either by changing the tool rotation rate $(\omega)$ or ratio of $\omega$ and tool traverse speed $(v)$. Sato et al. ${ }^{[16]}$ varied $\omega$ from 800 to $2450 \mathrm{rpm}$ and obtained a mean grain size ranging from $5.9 \mu \mathrm{m}$ to $17.8 \mu \mathrm{m}$. Similarly, by varying $\omega$ from 560 to $1840 \mathrm{rpm}$, Kwon et al. ${ }^{[12]}$ obtained grains ranging from $0.5 \mu \mathrm{m}$ to $4 \mu \mathrm{m}$ in size. By decreasing the $\omega / v$ ratio, $\mathrm{Ma}$ et $a{ }^{[17]}$ showed a decrease in grain size. The current alloy system contains $\mathrm{Al}_{3}(\mathrm{Sc}, \mathrm{Zr})$ dispersoids. Due to the very low diffusivity of $\mathrm{Sc}$ in $\mathrm{Al},{ }^{[32,33]}$ thermal stability of $\mathrm{Al}_{3}(\mathrm{Sc}, \mathrm{Zr})$ is exceptionally high and coarsening kinetics is very sluggish even at peak temperature typically reached during FSP. Jones et al. ${ }^{[34]}$ have reported the coarsening of precipitates as a function of temperature for Al-0.25 wt pct Sc. One hour annealing at $773 \mathrm{~K}\left(500{ }^{\circ} \mathrm{C}\right)$ led to a precipitate size of $20 \mathrm{~nm}$ in this alloy. Lee et al. ${ }^{[35]}$ reported a precipitate size of 25 to $60 \mathrm{~nm}$ after a solution treatment of A1-Mg-Sc-Zr alloy for 1 hour at $883 \mathrm{~K}\left(610^{\circ} \mathrm{C}\right)$. After tensile testing at $673 \mathrm{~K}\left(400^{\circ} \mathrm{C}\right)$ at $10^{-2} \mathrm{~s}^{-1}$ of this alloy in the ECAP condition, secondary $\mathrm{Al}_{3}(\mathrm{Sc}, \mathrm{Zr})$ precipitates were about $5 \mathrm{~nm}$ in size. Works of Jones
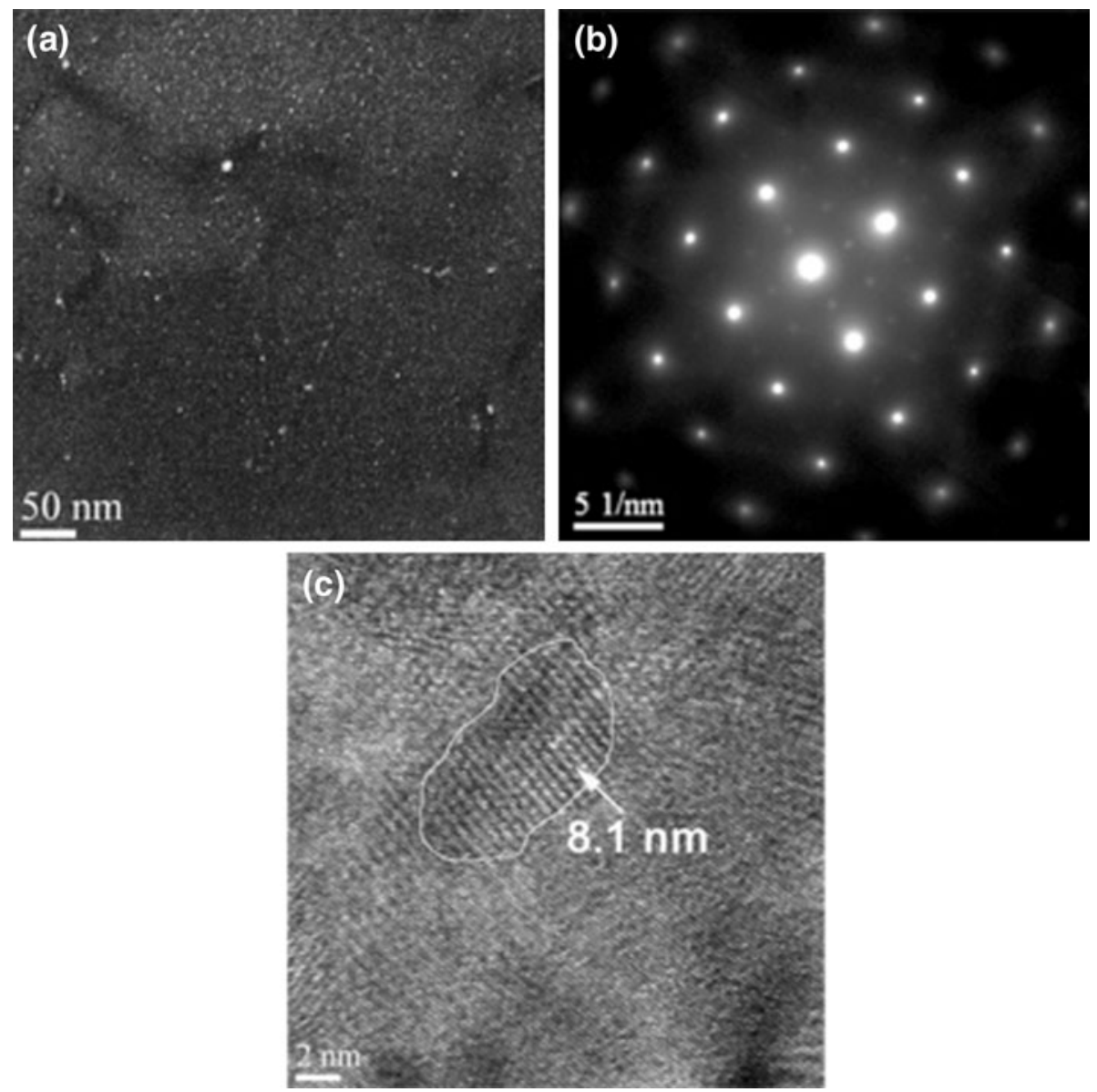

Fig. 10 - (a) Dark-field image showing secondary $\mathrm{Al}_{3}(\mathrm{Sc}, \mathrm{Zr})$ dispersoids, (b) corresponding selected-area diffraction (SAD) pattern, and (c) highresolution TEM image showing nanosized $\mathrm{Al}_{3}(\mathrm{Sc}, \mathrm{Zr})$ dispersoids. 
Table II. Values of Different Parameters Used in the Calculation of Zener-Hollomon Parameter and Heat Input at Different Tool Rotation Rates

\begin{tabular}{lcccccccccc}
\hline$\omega(\mathrm{rpm})$ & $\mathrm{APR}(\mathrm{mm} / \mathrm{rev})$ & $l_{\max }(\mathrm{mm})$ & $t(\mathrm{~s})$ & $\varepsilon_{\max }$ & $\dot{\varepsilon}_{\mathrm{Max}}\left(\mathrm{s}^{-1}\right)$ & $T\left[\mathrm{~K}\left({ }^{\circ} \mathrm{C}\right)\right]$ & $\mathrm{Z}\left(\mathrm{s}^{-1}\right)$ & $\tau(\mathrm{MPa})$ & $P^{*}(\mathrm{MPa})$ & $Q^{*}(\mathrm{~kW})$ \\
\hline 800 & 0.254 & 15.4 & 0.075 & 8.2 & 109 & $834(561)$ & $1.32 \times 10^{11}$ & 43.6 & $102.6(112.3)$ & $0.321(0.331)$ \\
400 & 0.508 & 15.4 & 0.15 & 6.8 & 45 & $789(516)$ & $1.79 \times 10^{11}$ & 44.7 & $98.6(113.9)$ & $0.161(0.169)$ \\
325 & 0.625 & 15.4 & 0.185 & 6.4 & 35 & $766(503)$ & $2.02 \times 10^{11}$ & 45.2 & $114.7(125.2)$ & $0.138(0.143)$ \\
\hline
\end{tabular}

*The terms in the brackets correspond to the materials in aged + FSP conditions.

et $a .^{[34]}$ and Lee et al. ${ }^{[35]}$ show the thermal resistance of $\mathrm{Al}_{3} \mathrm{Sc}$ or $\mathrm{Al}_{3}(\mathrm{Sc}, \mathrm{Zr})$ toward coarsening and dissolution as well. Hence, these precipitates provide sufficient pinning force on the grain boundaries of refined microstructure and retard the grain growth. Present authors have shown in a recent publication ${ }^{[20]}$ that Zener limiting grain size relationship can be used to predict the observed grain size of present FSP Al-Mg-Sc alloy. The effectiveness of dispersoids in inhibiting the grain growth during FSP has been shown in the past. $^{[14,36,37]}$

\section{B. Zener-Hollomon Parameter and Grain Refinement}

Unlike other SPDs, FSP is considered a high-temperature thermomechanical process due to the intense heat generated during the processing. The high temperature deformation process is most generally expressed in terms of the temperature-compensated strain rate, also known as the Zener-Hollomon parameter $(Z)$.

$$
Z=\dot{\varepsilon} \exp \left(\frac{Q}{R T}\right)
$$

where $\dot{\varepsilon}$ is the strain rate $\left(\mathrm{s}^{-1}\right), Q$ is the activation energy $\left(145 \mathrm{~kJ}^{-\mathrm{mol}^{-1}}\right.$ for $\mathrm{Al}$ alloy $\left.{ }^{[3]}\right)$ of the deformation process, $\mathrm{R}$ is the universal gas constant $\left(\mathrm{J}-\mathrm{mol}^{-1}\right.$. $\mathrm{K}^{-1}$ ), and $T$ is temperature $(\mathrm{K})$.

There have been a few attempts in the past to correlate grain size and $Z .^{[39,40]}$ To calculate $Z$, accurate knowledge of strain rate in the process is very important. Studies related to this have been carried out by many groups ${ }^{[38,41-46]}$ using experimental, analytical, and numerical methods. However, no work reported so far is capable of describing strain rate satisfactorily partly due to simplification and partly due to poor understanding of actual material flow process during FSP. In the current work, the model proposed by Long et al. ${ }^{[45]}$ to calculate strain was used. The strain rate was calculated from estimated strain. The expression for strain is given as

$$
\begin{gathered}
\varepsilon=\ln \left(\frac{l}{\mathrm{APR}}\right)+\left|\ln \left(\frac{l}{\mathrm{APR}}\right)\right| \\
l=2 R_{\text {pin }} \cos ^{-1}\left(\frac{R_{\mathrm{pin}}-a}{R_{\text {pin }}}\right)
\end{gathered}
$$

where $\varepsilon$ is strain, $l$ is deformed length, APR is tool advance per revolution, $R_{\text {pin }}$ is the tool pin radius, and $a$ is the distance of the streamline in question from the retreating side of the tool. Since a tapered tool was used in this study to process the material, an arithmetic average of pin radius at root and tool tip was used in the calculation of strain. The strain rate was estimated using the following expression

$$
\dot{\varepsilon}=\frac{\varepsilon}{t}
$$

Time $t$ was calculated by dividing APR by $v$. Using Eq. [2], the maximum strain was calculated. All the values used in the calculation of strain and strain rate are given in Table II. The knowledge of peak temperature during FSP is also essential to estimate $Z$. Since no experimental estimation of temperature was carried out in the current work, the peak temperature was estimated from the empirical relationship given by Arbegast and Hartley. ${ }^{[4]}$ It is given as

$$
\frac{T}{T_{m}}=K\left(\frac{\omega^{2}}{v \times 10^{4}}\right)^{\alpha}
$$

where $T, T_{\mathrm{m}}, K, v$, and $\alpha$ are peak temperature $\left({ }^{\circ} \mathrm{C}\right)$, melting point of the material being processed, a constant ranging from 0.65 to 0.75 , tool traverse speed (ipm), and a constant ranging from 0.04 to 0.06 , respectively. In the current calculation, $K$ equal to 0.75 and $\alpha$ equal to 0.06 were chosen to get the peak temperature during FSP. The estimated strain, strain rate, and $Z$ are given in Table II. The plot between grain size and $Z$ is shown in Figure 11.

Linear fitting to the experimental data led to following relationships:

$$
\begin{gathered}
\ln (d)=37.02-1.44 \ln (Z),(\mathrm{AR}+\mathrm{FSP}) \quad \text { and } \\
\ln (d)=43.92-1.72 \ln (\mathrm{Z})(\mathrm{Aged}+\mathrm{FSP})
\end{gathered}
$$

Evidently, an increase in $Z$ caused the grain size to decrease. A similar correlation between grain size and $Z$ has been shown to exist by many researchers for FSP materials. ${ }^{[38,39]}$

\section{Processing Parameters, Heat Input, and Grain Refinement}

In Figure 5(b), it was shown that the mean grain size increased with an increase in tool rotation rate. Temperature estimation using Arbegast and Hartley ${ }^{[47]}$ suggests that temperature increases with an increase in the tool rotation rate. The increase in temperature is intimately related to the amount of heat input, which is a function of processing parameter. Schmidt et al. ${ }^{[48]}$ 


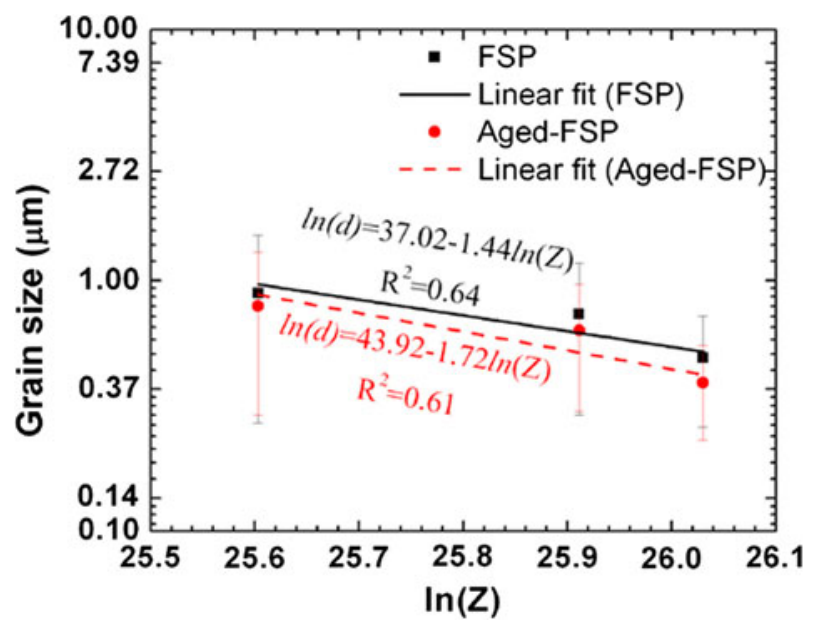

Fig. 11-Grain size variation for AR + FSP and aged + FSP TRC $\mathrm{Al}-\mathrm{Mg}-\mathrm{Sc}$ alloy as a function of the Zener-Holomon parameter.

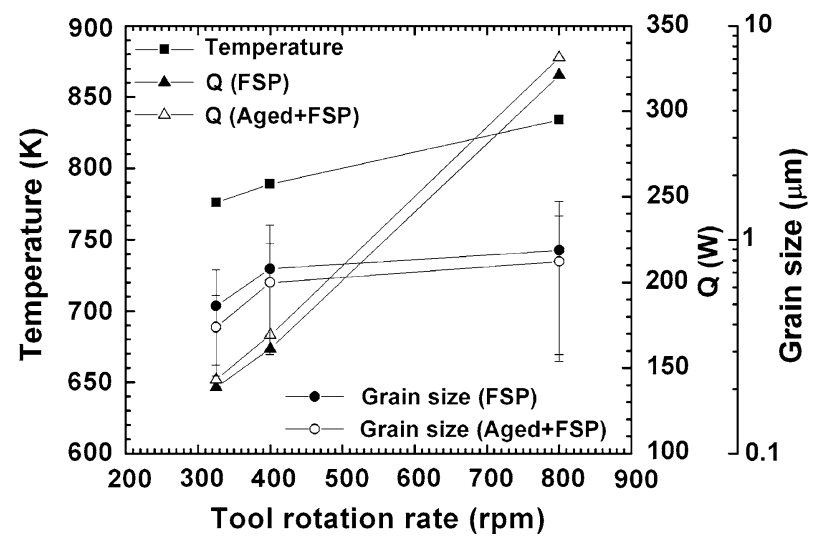

Fig. 12-Heat flux and temperature variations as a function of tool rotation rate. Also superimposed on it are mean grain sizes for the purpose of a comparison.

proposed an analytical model to estimate the heat input, which is given as

$$
\begin{aligned}
Q_{\text {total }}= & \frac{2}{3} \pi\left[\delta \tau_{\text {yield }}+(1-\delta) \mu p\right] \cdot \omega \cdot\left[\left[\left(R_{\text {shoulder }}^{3}-R_{\text {pin }}^{3}\right)\right.\right. \\
& \left.(1+\tan \alpha)+R_{\text {pin }}^{3}+3 R_{\text {pin }}^{2} H_{\text {pin }}\right]
\end{aligned}
$$

where $Q_{\text {total }}$ is heat flux $(\mathrm{J} / \mathrm{s}), \delta$ is the contact condition ( 0 for fully slip and 1 for fully stick condition; 0.65 in the present calculation ${ }^{[37]}$ ) at tool-workpiece interface, $\mu$ is the coefficient of friction equal to $0.4,{ }^{[37]} p$ is the axial pressure (MPa) imparted by the tool on the workpiece, $R_{\text {shoulder }}$ is the radius of the tool shoulder $(\mathrm{mm}), R_{\text {pin }}$ is the radius of the tool pin $(\mathrm{mm}), \alpha$ is the angle between tool convex shoulder surface and vertical plane (rad), and $H_{\text {pin }}$ is the height of the tool pin $(\mathrm{mm})$. The values related to tool geometry can be found in Table I. $\tau_{\text {yield }}$ is given as

$$
\tau_{\text {yield }}=\frac{\sigma_{\text {yield }}}{\sqrt{3}}
$$

where $\sigma_{\text {yield }}$ was calculated as

$$
\sigma_{\text {yield }}=\frac{1}{\alpha} \sinh ^{-1}\left[\left(\frac{Z}{A}\right)\right]^{1 / n}
$$

where $A, \alpha$, and $n$ are constants equal to $8.86 \times 10^{6} \mathrm{~s}^{-1}$, $0.045(\mathrm{MPa})^{-1}$, and 3.55, respectively. ${ }^{[38]}$ The calculated $Q_{\text {total }}$ is given in Table II along with shear stress and plunge force corresponding to each tool rotation rate. The heat flux and temperature as a function of tool rotation rate has been shown in Figure 12. To correlate these parameters with grain size values, the corresponding mean grain size values are also superimposed on the same plot.

As can be noted, peak temperature increased with an increase in the tool rotation rate. The increase in peak temperature is related to heat input, which is a function of shear stress, plunge force, and tool rotation rate for a given tool geometry. As expected, heat input was found to increase with an increase in tool rotation rate. High heat input resulted into the attainment of a higher peak temperature. Hence, it is evident that a higher tool rotation rate resulted into increase in peak temperature during the processing, and as a result, the mean grain size at higher tool rotation rate was found to be larger.

\section{Grain Refinement Mechanism}

A great deal of work has gone into understanding the mechanisms leading to grain refinement in FSP. It is understood that dynamic recrystallization (DRX) leads to such grain refinement. However, it is still not clear whether discontinuous DRX (DDRX), continuous DRX (CDRX), or particle stimulated nucleation (PSN) of recrystallization leads to grain refinement. McNelley et al. ${ }^{[49]}$ have considered all the models of DRX mentioned above and their applicability during FSP. Recently, a calculation by Kumar et al. ${ }^{[20]}$ showed that critical condition for nucleation of DDRX was not met during FSP of TRC Al-Mg-Sc alloy. Given the deformation conditions and microstructural characteristics of the current alloy, DRX via PSN also appears to be a distant possibility. Based on nucleus formation and nucleus growth, limited model Figure 13 has been constructed. The nucleus formation limited line was constructed using the following expression ${ }^{[50]}$ :

$$
d_{\mathrm{f}}=\left(\frac{\mathrm{K}_{1}}{T Z}\right)^{1 / 2}
$$

where $d_{\mathrm{f}}$ is the critical particle diameter needed for a zone formation and $\mathrm{K}_{1}$ is a constant that is equal to $7 a G D_{0 \mathrm{v}} / k$. Here, $a$ is the atomic volume, $G$ is the shear modulus, $D_{0 \mathrm{v}}$ is the preexponential bulk diffusion term, and $\mathrm{k}$ is the Boltzmann constant. Using this, $\mathrm{K}_{1}$ was found to be equal to $27.7 \mathrm{~m}^{2} \mathrm{~K} / \mathrm{s}$. The nucleus growth limited line was constructed using the following expression ${ }^{[50]}$ :

$$
d_{\mathrm{g}}=\frac{4 \gamma_{\mathrm{b}} \mathrm{K} G b}{3 \gamma_{\mathrm{s}} \sigma}
$$




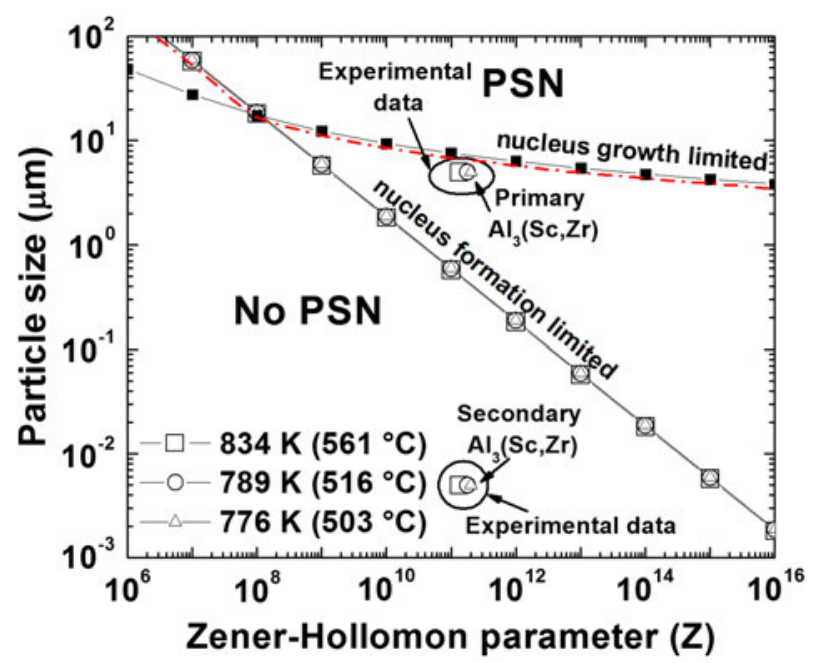

Fig. 13-Particle size $v s$ the Zener-Hollomon parameter $(Z)$ map showing condition for DRX via PSN.

where $d_{\mathrm{g}}$ is the critical particle size needed for the growth of zone formed around the particle, and $\gamma_{b}$ and $\gamma_{s}$ are grain boundary and subgrain boundary energy, respectively. The ratio $\gamma_{\mathrm{b}} / \gamma_{\mathrm{s}}$ was taken as 2 in the present calculation. ${ }^{[50]} \mathrm{K}$ is a constant equal to 28 for $\mathrm{Al}-\mathrm{Mg}$ alloy. ${ }^{[51]} \sigma$ was calculated using Eq. [10]. In the present alloy system, there are two types of particles: primary dispersoids and secondary dispersoids. The distribution histogram of primary dispersoids in as-cast and FSP (400 rpm) conditions are shown in Figure 9. The mean dispersoid size was $10.2 \mu \mathrm{m}$ and $5.1 \mu \mathrm{m}$, in as-cast and FSP conditions, respectively. The secondary dispersoids are expected to be in the range of 5 to $20 \mathrm{~nm}$. Primary and secondary dispersoid size with corresponding $Z$ values are shown in Figure 13. It can be seen that both sets of data points are below the dotted curves. It indicates that DRX via PSN will be unlikely for the current alloy system under the given deformation conditions. In an earlier paper, Kumar et al. ${ }^{[20]}$ showed that DRX via DDRX was also not possible for the same alloy system. Hence, DRX via geometric dynamic recrystallization (GDRX) appears to be a possibility. The role of GDRX in grain refinement of 2195Al alloy during FSW was considered by Prangnell and Heason. ${ }^{[52]}$ Further research is required to establish if GDRX is the mechanism leading to such a substantial grain refinement in this alloy.

\section{CONCLUSIONS}

FSP was used as an SPD tool to process UFG microstructure. FSP successfully produced a defect-free, bulk, equiaxed, and homogeneous UFG microstructure. By changing the process parameters, it was possible to control mean grain size and its distributions. Moreover, FSP led to a microstructure consisting mainly of highangle grain boundaries (as high as $\sim 95 \mathrm{pct}$ ). The distribution of misorientation angles was similar to the theoretical MacKenzie distribution for cubic polycrystalline material.
Using the model for DRX via PSN, it was concluded that in the current case, DRX cannot take place via PSN.

\section{ACKNOWLEDGMENT}

Authors would like to thank The Boeing Company, St. Louis, MO for supplying the materials and financial assistance.

\section{REFERENCES}

1. R.Z. Valiev, Y.D. Vishnyakov, R.R. Mulyukov, and G.S. Fainshtein: Phys. Status Solidi (A), 1990, vol. 117, pp. 549-53.

2. R.Z. Valiev, R.R. Mulyukov, V.V. Ovchinnikov, and V.A. Shabashov: Scripta Metall. Mater., 1991, vol. 25, pp. 2717-22.

3. H. Gleiter: Nanostruct. Mater., 1992, vol. 1, pp. 1-19.

4. K.Y. Mulyukov, S.B. Khaphizov, and R.Z. Valiev: Phys. Status Solidi (A), 1992, vol. 133, pp. 447-54.

5. N.A. Akhmadeev, N.P. Kobelev, R.R. Mulyukov, Y.M. Soifer, and R.Z. Valiev: Acta Metall. Mater., 1993, vol. 41, pp. 1041-46.

6. R.Z. Valiev and T.G. Langdon: Progr. Mater. Sci., 2006, vol. 51, pp. 881-981.

7. M.A. Meyers, A. Mishra, and D.J. Benson: Progr. Mater. Sci., 2006, vol. 51, pp. 427-556.

8. R.Z. Valiev, R.K. Islamgaliev, and I.V. Alexandrov: Progr. Mater. Sci., 2000, vol. 45, pp. 103-89.

9. A.P. Zhilyaev and T.G. Langdon: Progr. Mater. Sci., 2008, vol. 53, pp. 893-979.

10. Y. Saito, H. Utsunomiya, N. Tsuji, and T. Sakai: Acta Mater., 1999, vol. 47, pp. 579-83.

11. N. Tsuji, Y. Saito, S.-H. Lee, and Y. Minamino: Adv. Eng. Mater., 2003, vol. 5, pp. 338-44.

12. Y.J. Kwon, N. Saito, and I. Shigematsu: J. Mater. Sci. Lett., 2002, vol. 21, pp. 1473-76.

13. I. Charit and R.S. Mishra: Ultrafine Grained Materials III, Y.T. Zhu, T.G. Langdon, R.Z. Valiev, S.L. Semiatin, D.H. Shin, and T.C. Lowe, eds., TMS, Charlotte, NC, 2004, pp. 95-101.

14. Z.Y. Ma and R.S. Mishra: Scripta Mater., 2005, vol. 53, pp. 7580.

15. R.S. Mishra and Z.Y. Ma: Mater. Sci. Eng. R:, 2005, vol. 50, pp. $1-78$.

16. Y. Sato, M. Urata, and H. Kokawa: Metall. Mater. Trans. A, 2002, vol. 33A, pp. 625-35.

17. Z.Y. Ma, R.S. Mishra, and M.W. Mahoney: Acta Mater., 2002, vol. 50, pp. 4419-30.

18. J.Q. Su, T.W. Nelson, and C.J. Sterling: Philos. Mag., 2006, vol. 86 , pp. 1-24.

19. C.G. Rhodes, M.W. Mahoney, W.H. Bingel, and M. Calabrese: Scripta Mater., 2003, vol. 48, pp. 1451-55.

20. N. Kumar, R.S. Mishra, C.S. Huskamp, and K.K. Sankaran: Mater. Sci. Eng. A, 2011, vol. 528, pp. 5883-87.

21. L.S. Tóth, B. Beausir, C.F. Gu, Y. Estrin, N. Scheerbaum, and C.H.J. Davies: Acta Mater., 2010, vol. 58, pp. 6706-16.

22. J. K. Mackenzie: Biometrika, 1958, vol. 45, pp. 229-40.

23. Y.S. Sato, M. Urata, H. Kokawa, K. Ikeda, and M. Enomoto: Scripta Mater., 2001, vol. 45, pp. 109-14.

24. J.-Q. Su, T.W. Nelson, and C.J. Sterling: Scripta Mater., 2005, vol. 52, pp. 135-40.

25. N. Kumar, R. Mishra, C.S. Huskamp, and K. Sankaran: Scripta Mater., 2011, vol. 64, pp. 576-79.

26. J. Royset and N. Ryum: Int. Mater. Rev., 2005, vol. 50, pp. 19-43.

27. J.-Q. Su, T.W. Nelson, and C.J. Sterling: J. Mater. Res., 2003, vol. 18, pp. 1757-60.

28. J.D. Robson and L. Campbell: Sci. Technol. Weld. Join., 2010, vol. 15 , pp. 171-76.

29. N. Kumar, R. Mishra, C.S. Huskamp, and K. Sankaran: J. Mater. Sci., 2011, vol. pp. 1-7.

30. D.C. Hofmann and K.S. Vecchio: Mater. Sci. Eng. A, 2005, vol. 402, pp. $234-41$. 
31. M. Mehranfar and K. Dehghani: Mater. Sci. Eng. A, 2011, vol. 528, pp. 3404-08.

32. E. Clouet, A. Barbu, L. Laé, and G. Martin: Acta Mater., 2005, vol. 53 , pp. 2313-25.

33. E.A. Marquis and D.N. Seidman: Acta Mater., 2005, vol. 53, pp. 4259-68.

34. M.J. Jones and F.J. Humphreys: Acta Mater., 2003, vol. 51, pp. 2149-59.

35. S. Lee, A. Utsunomiya, H. Akamatsu, K. Neishi, M. Furukawa, Z. Horita, and T.G. Langdon: Acta Mater., 2002, vol. 50, pp. 55364.

36. I. Charit and R.S. Mishra: Acta Mater., 2005, vol. 53, pp. 4211-23.

37. F.C. Liu, Z.Y. Ma, and L.Q. Chen: Scripta Mater., 2009, vol. 60, pp. $968-71$.

38. R. Nandan, G. Roy, and T. DebRoy: Metall. Mater. Trans. A, 2006, vol. 37 , pp. $1247-59$.

39. C.I. Chang, C.J. Lee, and J.C. Huang: Scripta Mater., 2004 vol. 51, pp. 509-14.

40. K. Dehghani and A. Chabok: Mater. Sci. Eng. A, 2011, vol. 528, pp. 4325-30.

41. Z.W. Chen and S. Cui: IOP Conf. Series: Mater. Sci. Eng., 2009, vol. 4, p. 012026.
42. K.V. Jata and S.L. Semiatin: Scripta Mater., 2000, vol. 43, pp. 743-49.

43. S. Mukherjee and A.K. Ghosh: Mater. Sci. Eng. A, 2010, vol. 527, pp. $5130-35$.

44. K. Masaki, Y.S. Sato, M. Maeda, and H. Kokawa: Scripta Mater., 2008, vol. 58, pp. 355-60.

45. T. Long, W. Tang, and A.P. Reynolds: Sci. Technol. Weld. Joining, 2007, vol. 12, pp. 311-17.

46. G. Buffa, J. Hua, R. Shivpuri, and L. Fratini: Mater. Sci. Eng. A, 2006, vol. 419, pp. 381-88.

47. W.J. Arbegast and P.J. Hartley: Proc. $5^{\text {th }}$ Int. Conf. on Trends in Welding Research, 1998, Pine Mountain, GA, p. 541.

48. H. Schmidt, J. Hattel, and J. Wert: Modell. Simul. Mater. Sci. Eng., 2004, vol. 12, p. 143.

49. T.R. McNelley, S. Swaminathan, and J.Q. Su: Scripta Mater., 2008, vol. 58 , pp. $349-54$.

50. F.J. Humphreys and M. Hatherly: Recrystallization and Related Annealing Phenomena, 2nd ed., Pergamon Press, Oxford, U.K., 1995.

51. W. Blum: Plastic Deformation and Fracture of Materials, WileyVCH, New York, NY, 1993, pp. 359-405.

52. P.B. Prangnell and C.P. Heason: Acta Mater., 2005, vol. 53, pp. 3179-92. 